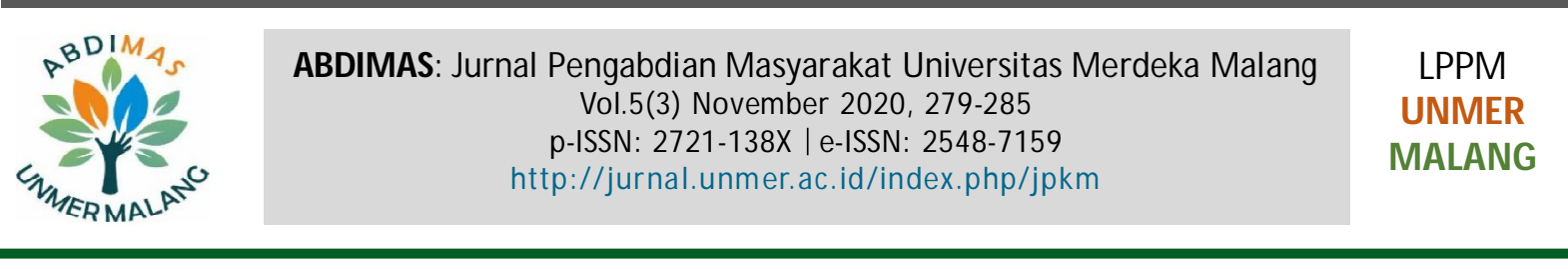

\title{
Pelatihan Membuat Produk Kerajinan Kreatif dari Sampah Kantong Plastik
}

\author{
Popy Yuliarty ${ }^{1}$, Rini Anggraini ${ }^{2}$ \\ ${ }^{1}$ Departemen Teknik Industri, ${ }^{2}$ Departemen Teknik Mesin, Fakultas Teknik \\ Universitas Mercu Buana, Jl. Raya, Meruya Selatan, DKI Jakarta, 11650, Indonesia
}

\section{ARTICLE INFO:}

Received: 2020-07-23

Revised: 2020-08-16

Accepted: 2020-10-28

\section{Keywords:}

Handicraft; Plastic bag;

Training; Waste

\section{ABSTRACT}

Continuous use of plastic will use up some non-renewable natural resources. Besides it produces several substances which are harmful to human health. Utilization of plastic waste is an effort to reduce plastic waste to a minimum that can be done by recycling. The large number of plastic bag waste around the environment has led to the idea of using it into creative products that have artistic and economic value for residents around the campus. Based on this background, a problem arises. The lack of ability to recycle plastic waste into valuable products, therefore a movement needed to educate and provide skills to the community to recycle plastic waste. The purpose of this activity is to provide education and provide training to the environment around the campus, especially housewives and young women to recycle money into crafts from used plastic bags in the hope that it can reduce waste and generate new business opportunities, namely handicraft handicrafts from used plastic bags. Implementation of activities, namely providing counseling and practical skills to make products from plastic bag waste. The expected end result is awareness from the community about the dangers of using plastic bags and the skills to recycle used plastic bags.

(C) 2020 Published by University of Merdeka Malang. This is an open access article distributed under the CC BY-SA 4.0 license (https://creativecommons.org/licenses/by-sa/4.0/)

How to cite: Yuliarty, P., \& Anggraini, R. (2020). Pelatihan Membuat Produk Kerajinan Kreatif dari Sampah Kantong Plastik. Abdimas: Jurnal Pengabdian Masyarakat Universitas Merdeka Malang, 5(3), 279-285.

https://doi.org/10.26905/abdimas.v5i3.4912

\section{PENDAHULUAN}

Berdasarkan data dari Kementrian Lingkungan Hidup dan Kehutanan bahwa total jumlah sampah Indonesia di 2019 akan mencapai 68 juta ton, dan sampah plastik sebesar 9,52 juta ton. Kementrian Lingkungan Hidup dan Kehutanan menargetkan pengurangan sampah plastik lebih dari 1,9 juta ton hingga tahun 2019 (Purwaningrum, 2016). Pemakaian plastik secara terus menerus akan menghabiskan beberapa sumber daya alam yang tidak dapat diperbaharui. Selain itu, menghasilkan beberapa zat yang berbahaya bagi kesehatan manusia. Plastik adalah salah satu bahan yang dapat ditemui di hampir disetiap produk. 
ABDIMAS: Jurnal Pengabdian Masyarakat Universitas Merdeka Malang

Volume 5, No 3, November 2020: 279-285

Penggunaan plastik yang tidak sesuai persyaratan akan menimbulkan berbagai gangguan kesehatan, karena dapat mengakibatkan pemicu kanker dan kerusakan jaringan pada tubuh manusia (karsinogenik). Selain itu plastik pada umumnya sulit untuk didegradasikan (diuraikan) oleh mikro organisme. Sampah plastik dapat bertahan hingga bertahun-tahun sehingga menyebabkan pencemaran terhadap lingkungan (Karuniastuti, 2013). Gerakan Indonesia Diet Kantong Plastik (GIDKP) merupakan perkumpulan nasional yang berfokus untuk mengedukasi masyarakat akan bahaya penggunaan kantong plastik. Sejak resmi berdiri tahun 2013, Gerakan Indonesia Diet Kantong Plastik bersama lembaga penggiat isu lingkungan memiliki tujuan untuk meningkatkan partisipasi masyarakat secara individu maupun lembaga. Gerakan ini muncul atas keprihatinan terhadap dampak dari sampah kantong plastik (Setiawan \& Fithrah, 2019).

Pemanfaatan limbah plastik merupakan upaya menekan pembuangan plastik semaksimal mungkin yang dapat dilakukan dengan mendaur ulang (Ramadhan et al., 2020). Daur ulang adalah proses untuk menjadikan suatu bahan bekas menjadi bahan baru dengan tujuan mencegah adanya sampah yang sebenarnya dapat menjadi sesuatu yang berguna, mengurangi penggunaan bahan baku yang baru, mengurangi penggunaan energi, mengurangi polusi dan emisi gas rumah kaca jika dibandingkan dengan proses pembuatan barang baru. Daur ulang adalah salah satu strategi pengelolaan sampah padat yang terdiri atas pemilahan, pengumpulan, pemrosesan, pendistribusian dan pembuatan produk/material bekas pakai, dan komponen utama dalam manajemen sampah modern dan bagian ke tiga dalam proses hierarkhi sampah 4R (reduce, reuse, recycle, and replace) (Yuliarty et al., 2019). Wawasan mengenai pentingnya 4R (reduce, reuse, recycle, replace, replace) dan kegunaan bank sampah sebagai langkah pertama dalam pengolahan sampah guna menciptakan kondisi lingkungan yang bersih dan ekonomis perlu dipahami oleh setiap orang (Kusminah, 2018). Material yang bisa didaur ulang terdiri dari sampah kaca, plastik, kertas, logam, tekstil dan barang elektronik. Sampah plastik dapat diolah menjadi kerajinan yang menarik dan bermanfaat serta bernilai jual tinggi karena memiliki tekstur dan warna yang beragam dan indah. Cara pengolahan dan pembuatannya juga relatif mudah dan siapa saja bisa melakukannya (Aminudin \& Nurwati, 2019).

Sampah ini dapat dijadikan sampah komersial atau sampah yang laku dijual untuk dijadikan produk lainnya sehingga apabila diolah lebih lanjut dapat menghasilkan keuntungan (Budiono, 2017). Sampah atau limbah plastik tersebut bisa dijadikan sebagai sejumlah hasil kerajinan tangan atau produk daur ulang. Tentunya, dengan modal yang tidak besar, tapi keuntungan yang didapat justru sebaliknya. Melansir dari buku Peluang Usaha untuk Ibu Rumah Tangga M odal 1 Juta Karya (Primasetra, 2010), berikut beberapa tips untuk memulai usaha yang berbahan dasar limbah plastik: (1) Buat perencanaan bisnis yang matang, rencanakan segala persiapan mulai dari tempat usaha hingga tenaga SDM yang dibutuhkan; (2) Cari supplier atau tukang dari barang bekas atau bahan dasar yang dibutuhkan yakni sampah plastik seperti bungkus mie instan atau produk sachet yang masih memungkinkan untuk diolah; (3) Persiapkan sejumlah alat dan peralatan yang dibutuhkan; (4) Mulai usaha dengan kelompok kecil. Hal tersebut tentunya untuk menghindari sejumlah risiko yang akan datang. Selain itu, dengan sedikitnya jumlah anggota atau SDM tentunya dapat memaksimalkan sumber daya yang ada; (5) Bersihkan sejumlah bahan dasar yang didapat, cuci hingga steril bahan dasar. Mengingat, bahan tersebut merupakan bahan limbah agar kebersihan produk tetap terjaga dan terhindar dari bakteri dan kuman penyakit; (6) Kreasikan dan inovatif pada produk. Padu padankan sampah plastik satu dengan yang lainnya. Bisa dikombinasikan pula dengan bahan kertas, plastik, kaca atau kain; (7) Dalam hal perekatan bahan, perhitungkan tata letak gambar atau komposisi sampah plastik. Jangan asal tempel ya, pasalnya aspek visual adalah titik utama yang dijual dari 
bisnis tersebut selain isu ramah lingkungan; (8) Jangan lupa, berikan label nama pada produk. Karena kehadiran label akan membuat produk terlihat semakin elegan dan meningkatkan kesan positif.

Pada kegiatan pengabdian masyarakat ini, sampah difokuskan kepada pengolahan sampah kantong plastik bekas. Sampah ini dapat dengan mudah ditemukan disekitar lingkungan masyarakat, misalnya disekitar kampus dan dilingkungan rumah tangga dan sebagainya. Sayang jika dibuang, bila dibakar juga dapat menyebabkan polusi udara. Dari sampah ini, muncullah ide untuk memanfaatkannya menjadi produk kreatif yang bernilai seni dan ekonomis. Gambar 1 adalah contoh-contoh plastik bekas yang bisa didaur ulang.
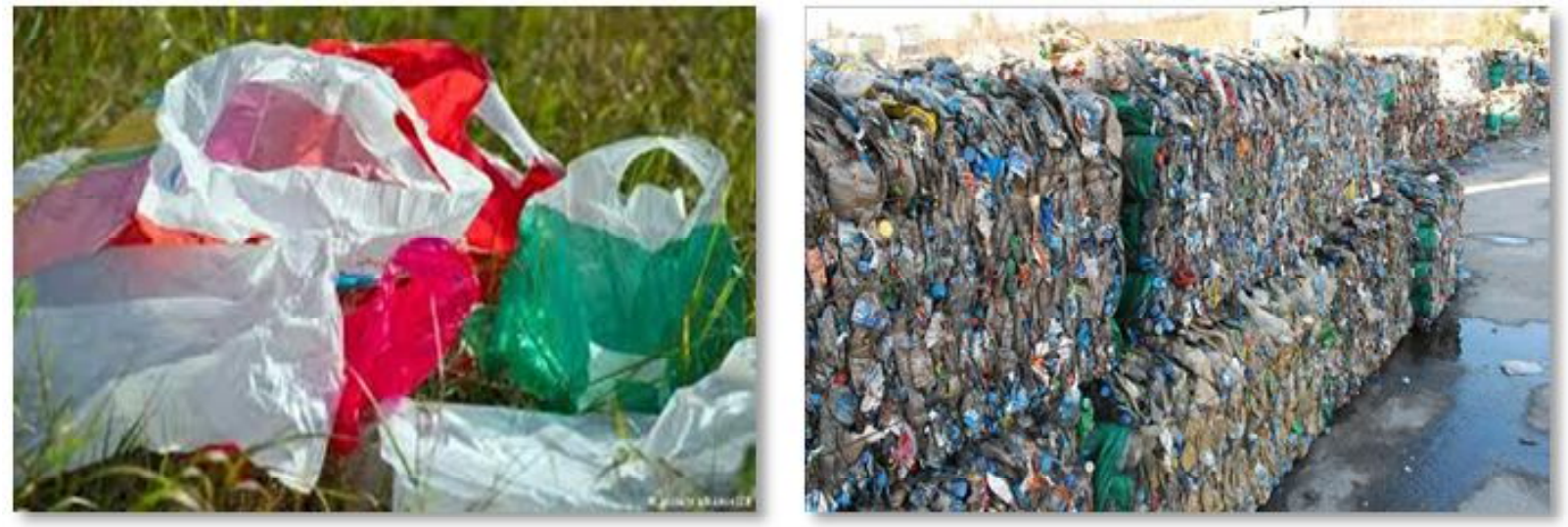

Gambar 1. Contoh kantong plastik bekas

Salah satu tujuan dibentuknya RPTRA (Ruang Publik Terpadu Ramah Anak) adalah untuk meningkatkan sarana dan prasarana kegiatan sosial warga termasuk pengembangan pengetahuan dan keterampilan kader PKK yang bekerja untuk meningkatkan pendapatan keluarga. Oleh karena itu pentingnya kegiatan ini adalah membantu masyarakat dalam meningkatkan ketrampilan sehingga mampu membuka peluang usaha khususnya dalam pembuatan kerajinan tanganPelatihan mendaur ulang sampah plastik ini nantinya diharapkan akan dapat memberikan nilai tambah bagi para peserta serta yang lebih penting lagi adalah memanfaatkan sampah menjadi produk bernilai (Ariyanti \& Lubis, 2019). Peserta adalah para ibu rumah tangga di sekitar kelurahan Meruya Selatan Kembangan Jakarta Barat. Tujuan dari kegiatan ini adalah: (1) Memberikan penyuluhan pengetahuan tentang bahaya sampah plastik bagi kelestarian lingkungan hidup; (2) Memberikan pengetahuan tentang keterampilan membuat kerajinan dari kantong plastik bekas kepada ibu-ibu dan remaja putri di lingkungan pemukiman Kelurahan M eruya Selatan, Jakarta Barat; (3) Memberikan ide kreatif untuk untuk mendaur ulang sampah plastik lainnya menjadi produk bernilai.

Pada Kegiatan ini khususnya akan melakukam edukasi pada masyarakat mengenai penanganan sampah yang masih bisa dimanfaatkan untuk keperluan lain sehingga akan menambah nilai guna dari barang bekas atau sampah. Adapun sasaran dari kegiatan ini antara lain: para ibu rumah tangga baik yang tergabung dalam ibu-ibu PKK dan para remaja putri. Hasil luaran yang diharapkan dari kegiatan ini adalah: (1) Keterampilan yang akan didapatkan dari kegiatan ini diharapkan dapat berkontribusi mengurangi sampah plastik; (2) Peserta mendapakan pengetahuan dan keahlian untuk mendaur ulang sampah plastik menjadi produk bernilai; (3) Umpan balik dari peserta terhadap kegiatan ini dalam bntuk pengisian kuesioner. 
ABDIMAS: Jurnal Pengabdian Masyarakat Universitas Merdeka Malang

Volume 5, No 3, November 2020: 279-285

\section{METODE}

Universitas Mercu Buana memiliki program studi yang erat kaitannya dengan dunia industri (manufaktur \& jasa) yaitu Program Studi Teknik Industri. Dunia industri berkembang jenis dan jumlahnya serta besarnya, mulai dari industri kecil sampai industri besar. Sebagai salah satu Institusi Pendidikan terkemuka, sudah selayaknya bila dirasakan juga kiprahnya bagi khalayak umum. RPTRA di Kelurahan Meruya Selatan merupakan salah satu sasaran dari kegiatan Pengabdian Masyarakat Universitas Mercu Buana. RPTRA merupakan tempat umum yang boleh didatangi oleh siapa saja, namun hendaknya dapat memberikan manfaat sebesar-besarnya bagi pada pengunjungnya. Tim pengabdian masyarakat melihat kondisi ini ini sebagai hal yang positif. Selain itu tim pengabdian ini juga mempunyai kemampuan dalam melakukan pelatihan ini. Fokus pada pelatihan ini adalah memberikan pengetahuan dan praktek membuat keterampilan mengolah sampah plastik menjadi produk kreatif yang bernilai dan unik.

Kegiatan ini diikuti oleh mitra yang terdiri dari para ibu rumah tangga dan remaja putri sebanyak 11 orang yang berdomisili di Kelurahan Meruya Selatan, Kembangan Jakarta Barat Provinsi DKI Jakarta yang tergabung dalam ibu-ibu PKK dan remaja karang taruna.

Kegiatan pada dasarnya dapat dibagi ke dalam 2 (dua) kegiatan pokok yaitu (1) penyuluhan tenttang jumlah sampah plastik dan bagayanya bagi kelangsungan hidup di bumi dan tahap ke (2) yaitu praktek pelaksanaan pembuatan kerajinan dari kantong plastik bekas. Untuk pelaksanaan kegiatan ini dibutuhkan bahan-bahan sebagai berikut: (1) Kantong plastik warna merah, kuning, putih dan warna lainnya (usahakan plastik yang digunakan jangan terlalu tipis) untuk membuat kelopak bunga. Plastik warna hijau digunakan untuk membuat daun dan menutup tangkainya; (2) Gunting untuk menggunting pola daun; (3) Kawat untuk tangkai daun; (4) Setrika untuk mengeraskan kantong plastik.

Adapun prosedur kerja untuk membuat kerajinan ini secara garis besar adalah membuat pola daun pada selembar kertas kemudian memotong kantong plastik sesuai pola dengan menggunting membentuk tulang daun, kemudian memakai energi panas (menggunakan setrika pakaian) untuk mengeraskan lembaran kantong plastik agar menjadi kaku. Ilustrasi proses dapat dilihat pada Gambar 2.

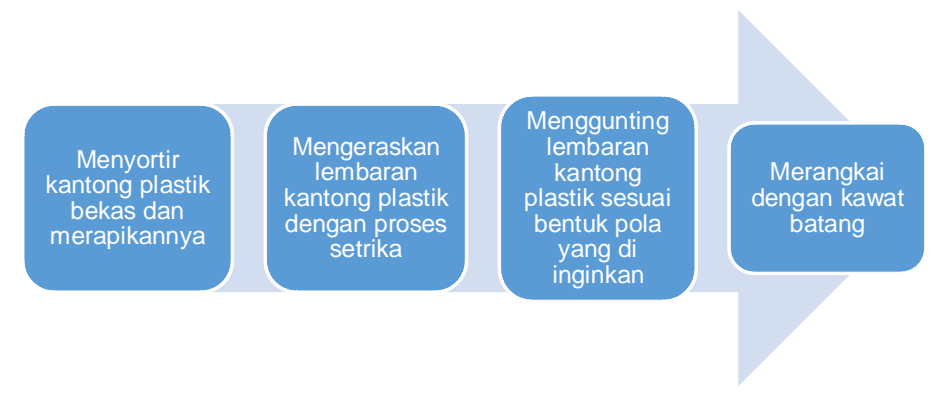

Gambar 2. Proses transformasi kantong plastik bekas menjadi produk kreatif.

Teknik menyetrika bahan plastik dimaksudkan agar mendapatkan texture kantong plastik menjadi kaku. Teknik ini sangat bergantung pada keahlian tiap individu. Tingkat kepanasan suhu alat setrika sangat mempengaruhi hasil daun plastik. Suhu yang terlalu panas akan menyebabkan kantong plastik meleleh dan bila kurang panas, antara lebaran kantong plastik tidak menyatu dan tidak kaku. Jadi tujuan melakukan penyetrikaan adalah untuk mendapatkan kantong plastik yang kaku sekaligus berkilau. Gambar 3 adalah contoh sederhana teknik menyetrika kantong plastik. Sedangkan produk kreatif yang akan dibuat dapat dilihat pada Gambar 4. 

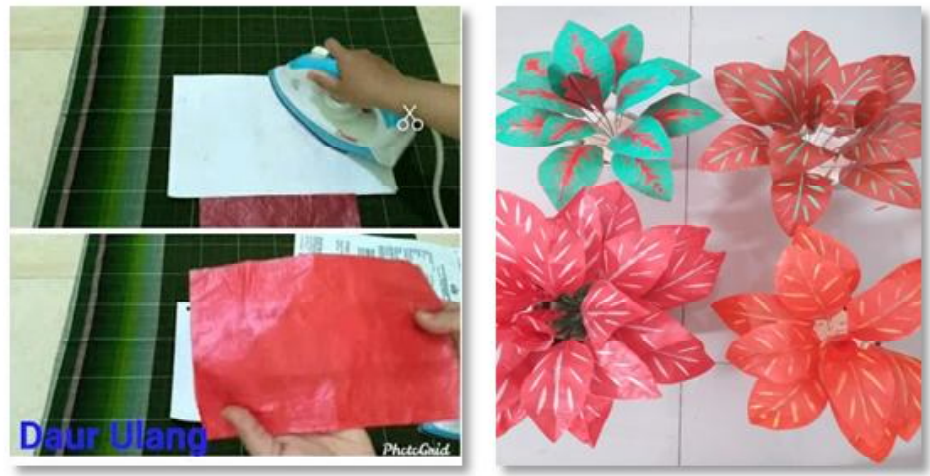

Gambar 3. Teknik menyetrika kantong plastik

Gambar 4. Produk yang akan dibuat
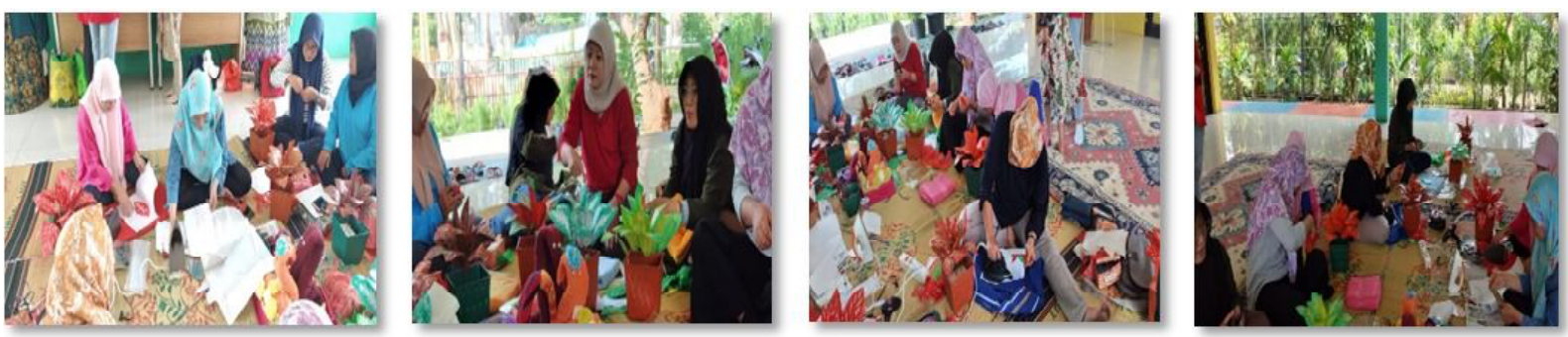

Gambar 5. Dokumentasi pelaksanaan kegiatan

\section{HASIL DAN PEMBAHASAN}

Bahan pelatihan dibagikan pada peserta terkait materi teoritis mapun praktek. Materi pelatihan langsung di ajarkan dan dipraktekkan oleh peserta tahap demi tahap. Peserta dibagi dalam beberapa kelompok untuk memudahkan penyerapan teknik pembuatan produk dengan baik mengingat materi kali ini menyangkut tentang keterampilan tangan karena tergolong dalam produk handmade. Bahan pelatihan sepenuhnya disiapkan oleh tim pelaksana dan boleh di bawa pulang oleh peserta. Pihak RPTRA memfasilitasi kegiatan ini dengan sangat kooperatif sehingga kegiatan berjalan lancar. Gambar 6 adalah hasil akhir dalam bentuk fisik produk yang bisa dihasilkan dari kegiatan ini.

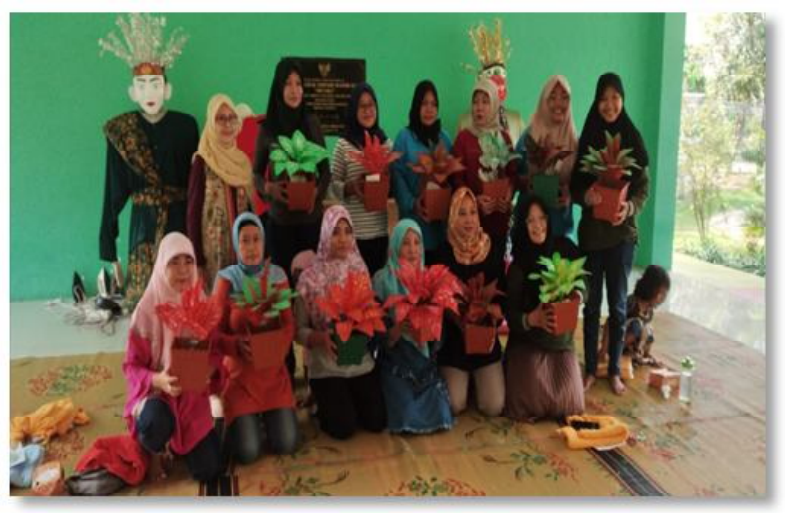

Gambar 6. Foto bersama produk akhir yang dihasilkan dari kegiatan pengabdian masyarakat 
ABDIMAS: Jurnal Pengabdian Masyarakat Universitas Merdeka Malang

Volume 5, No 3, November 2020: 279-285

\section{Evaluasi Kegiatan}

Untuk mengetahui sejauh mana keberhasilan dari kegiatan pengabdian ini, maka dilakukan evaluasi dengan cara penyebaran kuisioner kepada para peserta. Teknik pengolahan kuaisoner dengan merataratakan hasil penialain yang diberikan oleh para peserta. Hasil rekapitulasi penilaian peserta terhadap tiap kriteria penilaian dapat dilihat pada Tabel 1.

Tabel 1. Rekapitulasi kuisioner evaluasi kegiatan

\begin{tabular}{lc}
\hline \multicolumn{1}{c}{ Kriteria yang dinilai } & Rata-Rata \\
\hline Manfaat kegiatan bagi peserta & 4 \\
Waktu pelaksanaan kegiatan & 3,50 \\
Lamanya waktu pelaksanaan kegiatan & 3 \\
Isi / materi kegiatan & 4 \\
Penjelasan instruktur tentang materi kegiatan & 4 \\
Kesediaan instruktur menjelaskan selama praktek & 4 \\
Alat bantu untuk keperluan kegiatan & 4 \\
Konsumsi bagi peserta & 4 \\
Kelanjutan kegiatan yang sejenis untuk masa yang akan datang & 4 \\
\hline
\end{tabular}

Berdasarkan rekapitulasi dapat disimpulkan bahwa secara umum kegiatan ini dapat dikategorikan berhasil, peserta menganggap bahwa kegiatan ini sangat bermanfaat untuk menunjang kelancaran tugas mereka dan berharap di masa yang akan datang dapat diberikan pelatihan yang sejenis. Nilai terendah adalah pada penilaian "lamanya waktu pelaksanaan" kegiatan yaitu rata-ratanya 3, karena memerlukan praktek langsung, maka apabila akan mengadakan kegiatan sejenis, maka lamanya waktu kegiatan mungkin perlu ditambah, sehingga seluruh peserta pelatihan benar-benar dapat mempraktekkan dengan baik.

\section{SIMPULAN DAN SARAN}

\section{Simpulan}

Kesimpulan yang bisa diambil dari kegiatan pengabdian pada masyarakat ini adalah: (1) Masyarakat peserta pelatihan telah mendapatkan pengetahuan tentang bahaya sampah plastik bagi lingkungan hidup melalui penyuluhan yang telah diberikan serta melakui diskusi interaktif yang dilakukan antara peserta dengan tim pelaksana kegiatan; (2) Masyarakat peserta telah mendapatkan keterampilan dan mampu mendaur ulang kantong plastil bekas menjadi produk yang lebih bernilai; (3) Berdasarkan hasil kuisioner menunjukkan adanya tanggapan yang positif dari para peserta terhadap kegiatan ini.

\section{Saran}

Berdasarkan dari urut-urutan kegiatan sampai pada penyelesaian kegiatan, maka saran yang dapat kami berikan yaitu: (1) Kegiatan pengabdian masyarakat seperti ini mendapatkan tanggapan positif dari masyarakat, maka harus terus dikembangkan secara berkelompok dan terprogram; (2) Perlu ada kegiatan lanjutan yang terorganisir untuk melihat dampaknya kepada peserta pelatihan, baik positif maupun negatif untuk menjadi pembelajaran bagi pelaksana; (3) Para peserta dapat memanfatkannya untuk melatih jiwa kewirausahaan. 


\section{DAFTAR PUSTAKA}

Aminudin, A. \& Nurwati, N. (2019). Pemanfaatan sampah plastik menjadi kerajinan tangan guna meningkatkan kreatifitas warga sekitar Institut Teknologi dan Bisnis Ahmad Dahlan ( ITB-AD ) Jakarta. Jurnal Abdimas BSI Jurnal Pengabdian Kepada Masyarakat, 2(1), 66-79. https://doi.org/10.31294/jabdimas.v2i1.4515

Ariyanti, S., \& Lubis, M. S. Y. (2019). Training of hand crafts with silicone mold method for the people of Meruya Selatan. ICCD, 2(1), 451-455. https://doi.org/10.33068/iccd.vol2.iss1.183

Budiono, B. (2017). Pemanfaatan limbah botol plastik menjadi prakarya boneka pinguin sebagai bentuk implementasi dari pendidikan lingkungan hidup. PINUS: Jurnal Penelitian Inovasi Pembelajaran, 2(2) 113-117. https://doi.org/10.29407/pn.v2i2.716

Karuniastuti, N. (2013). Bahaya plastik terhadap kesehatan dan lingkungan. Swara Patra: M ajalah PPSDM Migas, 3(1).

Kusminah, I. L. (2018). Penyuluhan 4R (reduce, reuse, recyle, replace) dan kegunaan bank sampah sebagai langkah menciptakan lingkungan yang bersih dan ekonomis di Desa Mojowuku Kabupaten Gresik. Jurnal Pengabdian M asyarakat, 3(01), 22-28.

https://doi.org/10.30996/jpm17.v3i01.1165

Primasetra, A. (2010). Peluang Usaha untuk Ibu Rumah Tangga Modal 1 Juta. Pustaka Grhatama.

Purwaningrum, P. (2016). Upaya mengurangi timbulan sampah plastik di lingkungan. Indonesian Journal of Urban and Environmental Technology, 8(2), 141.

https://doi.org/10.25105/urbanenvirotech.v8i2.1421

Ramadhan, A., Lelo, L., \& Rasyid, R. (2020). Pelatihan pemanfaatan sampah plastik sebagai material produk hiasan bagi lulusan SMA di Kota Tangerang. Abdimas: Jurnal Pengabdian Masyarakat Universitas Merdeka Malang, 5(1), 1-17. https://doi.org/10.26905/abdimas.v5i1.3083

Setiawan, B., \& Fithrah, D. S. (2019). Kampanye gerakan indonesia diet kantong plastik dalam membentuk persepsi masyarakat Bandung. Jurnal Manajemen Komunikasi, 2(2), 102. https://doi.org/10.24198/jmk.v2i2.12909

Yuliarty, P., Anggraini, R., \& Kristiana, R. (2019). Daur ulang karton bekas menjadi produk bernilai. Industri Inovatif/ : Jurnal Teknik Industri, 9(2), 41-46. https://doi.org/10.36040/industri.v9i2.371 